\title{
Resistance to European Corn Borer in Processing Sweet Corn
}

\author{
Jeffrey Gardner ${ }^{1}$ and Michael P. Hoffmann ${ }^{2}$ \\ Department of Entomology, Insectary Building, Cornell University, Ithaca, \\ NY 14853 \\ Margaret E. Smith ${ }^{2}$ \\ Department of Plant Breeding, Cornell University, Ithaca, NY 14853
}

Additional index words. damage scale, maturation rate, Ostrinia nubilalis, Zea mays

\begin{abstract}
Trials were conducted in 1997 and 1998 to determine if there is a range of resistance to European corn borer [Ostrinia nubilalis (Hübner)] (ECB) in commercially available processing sweet corn (Zea mays $\mathrm{L}_{\text {.). }}$. Twelve processing corn cultivars were tested in 1997 and 18 cultivars in 1998. About 40 first instar larvae of colony-reared ECB were used to infest plants in both whorl and silking stages of growth. At harvest, plants infested at the whorl stage were evaluated for numbers of larvae and larval tunnels, and length of larval tunnels. Plants infested at the silking stage were evaluated for number of larvae per ear and were rated for ear damage using a 9-point scale. Resistance rankings among cultivars were consistent between years and between silk- and whorl-infested plants. We conclude that there is a substantial range of resistance already present in processing sweet corn cultivars, and that resistance is probably a combination of both exclusion and suppression of feeding. Our findings have two immediate uses: incorporation into existing IPM programs and incorporation of identifiable resistance bearing cultivars into a long-term breeding program for resistance to ECB in sweet corn.
\end{abstract}

Sweet corn is a valuable crop in the northeastern United States, where the most important insect pest is the European corn borer, Ostrinia nubilalis (Hübner) (Lepidoptera: Crambidae). Nationally in 1998, $\approx 300,000$ ha of fresh-market and processing sweet corn were planted. In nine northeastern states, $\approx 30,000$ ha of fresh-market sweet corn are grown each year (National Agricultural Statistics Service, 1999). New York State is one of the leaders in the U.S. production of fresh-market and processing sweet corn, with revenues from 25,500 ha estimated at about \$38 million in 1997 (National Agricultural Statistics Service, 1998). Because the crop is valuable and worm-contaminated sweet corn is unacceptable to customers, farmers use multiple insecticide applications to minimize corn borer damage. Of surveyed states in the United States, $\approx 89 \%$ of the fresh-market sweet corn and $74 \%$ of the processing corn acreage is sprayed with insecticides (National Agricultural Statistics Service, 1997). In the northeastern United States, two to four insecticide applications are typically used per season to control European corn borer (ECB) in fresh-

\footnotetext{
Received for publication 18 May 1999. Accepted for publication 20 Dec. 1999. We thank the New York State Sweet Corn Research Association for their financial support. This research is a contribution to Regional Project NE-124, Genetic Manipulation of Sweet Corn Quality and Stress Resistance. The cost of publishing this paper was defrayed in part by the payment of page charges. Under postal regulations, this paper therefore must be hereby marked advertisement solely to indicate this fact. ${ }^{1}$ Research Support Specialist. E-mail address: jg48@cornell.edu.

${ }^{2}$ Associate Professor.
}

market sweet corn. Fewer applications are required in processing sweet corn, but often fields are treated. The extensive use of insecticides is expensive, increases the likelihood that resistance to insecticides will develop, poses environmental risks, and creates conflicts between agricultural and nonagricultural segments of our society. The recently enacted Food Quality Protection Act (FQPA) is evidence of changing attitudes toward pesticide use. Though sweet corn is not listed as an FQPA priority commodity, several insecticides currently used for control of ECB in sweet corn are considered priority pesticides and are in danger of losing registration (Cornell Cooperative Extension, 1999). The need is intensifying for alternative and complementary control tactics, such as genetic resistance to pests.

Most, if not all, resistance breeding in corn has been directed at minimizing damage caused by ECB larvae, although ovipositional preference by adults has been examined (Grier and Davis, 1980). In field corn for silage and grain, larval feeding within stalks can cause the corn to lodge, interfering with harvest. Also, shank boring can cause the ear to drop off the plant. Thus, the emphasis has been on minimizing damage to stalks and ear shanks. In sweet corn, however, ear feeding and contamination are the primary causes of economic loss. Quality requirements are less stringent in processing sweet corn than in fresh-market sweet corn, but cosmetic damage can render unmarketable the ears of both. In spite of the differences between sweet and field corn, the breeding effort is similar for both types. Although protection of the ear is the primary goal in freshmarket and processing sweet corn, there are three reasons to examine vegetative damage as well as ear damage. First, variation in ECB damage to vegetative structures among corn genotypes may indicate the range of resistance among cultivars. Secondly, resistance may help suppress the ECB population, minimizing the number of insects present when the corn is in the susceptible ear filling stage. This is particularly important in areas where the bivoltine (two generations) race of ECB is present (Carlson and Andrew, 1976). Lastly, since corn is the primary host of the pest, population declines in one year may contribute to reduced ECB populations in subsequent years.

The life history of ECB was described by Metcalf and Metcalf (1993). European corn borer overwinters as larvae, which pupate and emerge as adults in early spring. The adults mate and females lay clusters of eggs on the underside of corn leaves. Neonatal larvae emerge, begin feeding and eventually bore into stalk or ear tissue, depending on where and when the eggs were deposited. Damage to corn occurs by larvae feeding on leaves, or within the stalk, shank, and all parts of the ear. There are univoltine and bivoltine races of ECB (Eckenrode et al., 1983). In areas where the univoltine race predominates, host plant resistance should be directed at minimizing larval survival and any subsequent migration to the corn ear. In areas where the bivoltine race is predominant, that resistance is doubly important and should minimize damage, as well as suppress the ECB population.

The purpose of our research was to determine the range of resistance in commercially available processing sweet corn. Any cultivars with identifiable resistance could then be used in a long-term breeding program for ECB-resistant sweet corn. Although there is well established resistance in commercial field corn, conventional wisdom has been that most sweet corn hybrids are susceptible to ECB. Carlson and Andrews (1976) found a range of resistance in sweet corn, but that research did not include evaluation of stalk feeding. Others have published research on ECB resistance in sweet corn, but much of that work evaluated inbreds relative to a commercial control (Davis et al., 1993; Shehata et al., 1975; Warnock et al., 1998). So far, corn breeding research has not revealed a specific mechanism of resistance, but that resistance to ECB is widely believed to be a quantitative trait rather than a trait mediated by a single gene. Therefore, genesis of resistance-breaking races of ECB populations will probably be slow at best. In addition, traditional breeding programs that provide broad resistance may provide a sustainable platform for long-term effectiveness from $B t$-transformed corn cultivars.

\section{Materials and Methods}

To evaluate resistance, commercially available processing sweet corn cultivars were manually infested with ECB larvae in 1997 and 1998 at the Cornell Univ. Dept. of Entomology Research Farm located in Freeville, N.Y. Corn cultivars and producer information are listed in Table 1. The corn was grown using 
standard commercial practices, except that no insecticide was used. In both years, corn was planted manually using spacing of $\approx 30 \mathrm{~cm}$ between plants and $\approx 76 \mathrm{~cm}$ between rows. A preplant, banded application of $\approx 33 \mathrm{~kg} \cdot \mathrm{ha}^{-1} \mathrm{~N}$ (ammonium nitrate) was used, and $\approx 67 \mathrm{~kg} \cdot \mathrm{ha}^{-1} \mathrm{~N}$ was applied as a side dressing when plants were $\approx 30 \mathrm{~cm}$ tall. To control weeds, atrazine (Aatrex $4 \mathrm{~h}$ ) and metolachlor (Dual II) (Novartis Crop Protection, Greensboro, N.C.) were applied preemergence at the minimal labeled rates. There were two separate plantings each year, one for infestation with ECB larvae at whorl stage and one for

Table 1. Processor sweet corn cultivars and producer corporate office locations.

\begin{tabular}{|c|c|}
\hline Producer and location & Cultivar \\
\hline \multirow[t]{2}{*}{ Asgrow Seed Co., Saticoy, Calif. } & Rival \\
\hline & Maverick \\
\hline \multirow[t]{3}{*}{ Pillsbury Co., Le Seur, Minn. } & Code 22 \\
\hline & Code 243 \\
\hline & Code 46 \\
\hline \multirow[t]{5}{*}{ Harris Moran Seed Co., Modesto, Calif. } & Excalibur \\
\hline & Zenith \\
\hline & Bandit $^{\mathrm{z}}$ \\
\hline & Lumina $^{z}$ \\
\hline & Legacy $^{z}$ \\
\hline \multirow[t]{8}{*}{ Novartis Seeds Inc., Boise, Idaho } & GH2690 \\
\hline & Bonus \\
\hline & Primeplus \\
\hline & GH1703 \\
\hline & Jubilee \\
\hline & Sprint $^{\mathrm{z}}$ \\
\hline & GH2684z \\
\hline & Bold $^{z}$ \\
\hline
\end{tabular}

${ }^{\mathrm{z}}$ Cultivars tested in 1998 but not in 1997. infestation on silks. In 1997, plots for silk infestations were sown on 29 May while those for whorl infestation were sown on 12 June. In 1998 , plots for both infestations were sown on 21 May. Plants infested at the whorl stage were evaluated for stalk damage while those infested at silking were evaluated for ear damage only. In both years, a randomized complete-block experimental design was used, and each cultivar was replicated once per block in five blocks, using 20 plants per replicate for a total of 100 plants per cultivar to ensure adequate number of plants for infestation. Ten plants in each replication were infested, providing 50 plants for evaluation for each cultivar. Twelve commercial sweet corn cultivars were planted in 1997, but because of poor ear fill, no data were recorded for cultivar 'GH1703'. Six additional cultivars were used in 1998 (Table 2).

Infestation at the whorl stage was conducted when plants were at about the seven leaf stage (V7) and occurred within a 2-d period in both 1997 and 1998. First instar larvae were obtained from a colony maintained on meridic diet (Guthrie, 1971). To avoid inbreeding depression and loss of mandibles, the colony was refreshed annually using field-collected ECB. To collect larvae for infestations, ECB egg masses were placed in canning jars $(0.37 \mathrm{~L})$ using a light coating of atomized water to fix the eggs to the inside of the jars. Upon emergence from eggs, larvae were mixed with air-dried corn cob grits (J.R. Nielson and Sons, Windsor, Conn.). A device commonly called a "bazooka" was used to infest the corn plants (Wiseman et al., 1980). The device consisted of a reservoir and an offset orifice connected by a manually reciprocated bar drilled with a cylindrical hole. The hole filled with the grits/larvae mixture when positioned below the reservoir, and dispensed the mixture when positioned above the orifice. Larval density was adjusted to 20 larvae in each drop $(\approx 20 \% \mathrm{CV}, \mathrm{N}=5)$ of about $0.4 \mathrm{~mL}$ grits from the infestation device. Each plant received two drops administered within the leaf whorl, providing a total of 40 neonatal larvae per plant. Infestation at the silk stage was similar, except that in each replicate, plants were infested directly on the silks when silks were present on at least 10 plants in the replicate. In 1997, there were three infestation dates spanning $10 \mathrm{~d}$. In 1998, because of large differences in maturation rates, there were 10 infestation dates spanning $30 \mathrm{~d}$.

After infestation, plants were allowed to mature to harvest age and then destructively sampled. In the plots receiving a whorl infestation, all replicates were harvested by block when the latest maturing cultivar had matured. In 1997, all blocks were harvested and evaluated over a 7-d span. In 1998, only four blocks were harvested over a span of $13 \mathrm{~d}$. By harvest time, the earliest maturing cultivars were well past optimal harvest maturity, but the majority of cultivars were at or slightly past acceptable maturity. To assess resistance, 8-10 plants from each plot were split longitudinally and the number of larvae per stalk, number of tunnels, and length of tunnels were recorded. Mean length per tunnel was derived from the measured variables. In the plots infested at the silk stage, 10 ears per plot were harvested and evaluated for dam-

Table 2. Ranks, means, and 95\% confidence intervals for response variables from 2 years of experimentation to evaluate differences among commercial processing sweet corn cultivars manually infested with ECB neonatal larvae.

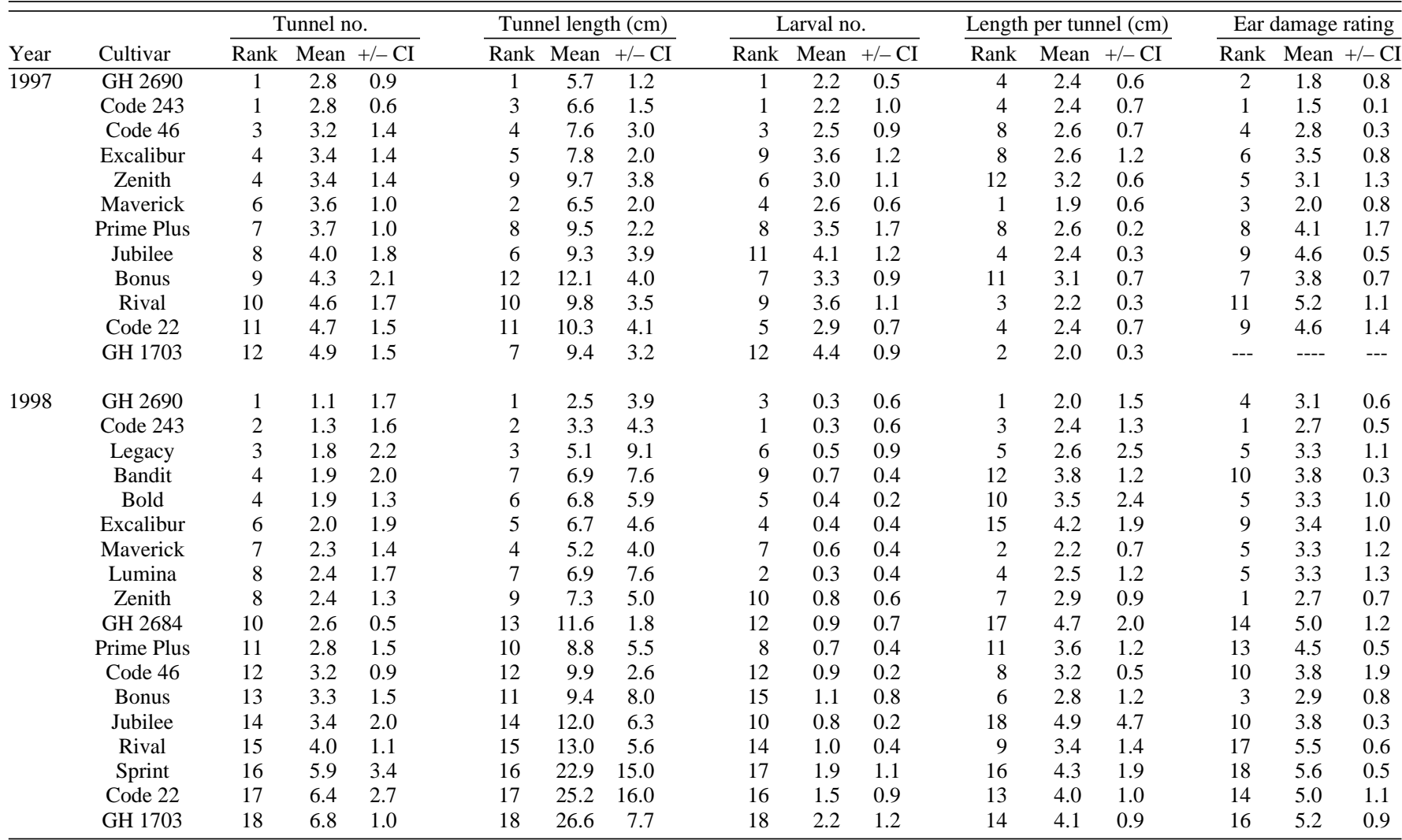


age once they had matured. Ear harvest and evaluation were conducted over 2-d spans in both years. Ear damage was estimated using a 9-point scale (Guthrie et al., 1978), nine representing the greatest damage.

Statistical analyses were conducted using analysis of variance (ANOVA) to corroborate the treatment differences observed in the field. Although the measured variables for individual plants were not normally distributed or homoscedastic, plot means were normal and homoscedastic. Treatments were separated by constructing $95 \%$ confidence intervals about the means for each cultivar (Jones, 1984; Jones and Matloff, 1986). Correlations among response variables were determined using Pearson product moment correlation. All statistical analyses were conducted using software from SAS (SAS Institute, Cary, N.C.) and SigmaStat (Jandel Scientific Software, San Rafael, Calif.)

\section{Results and Discussion}

Our results show that there is a range of resistance to ECB among commercial cultivars of processing sweet corn. Response variables were affected by the interaction of cultivar and year $(P \leq 0.05)$, so data are presented for each year. For both years, ANOVA confirmed field observations and indicated significant differences $(P \leq 0.05)$ among cultivars for all variables tested. Since six of the cultivars were tested in 1998 but not in 1997 (Table 2), conclusions regarding their performance should be tempered by that knowledge. Corn cultivars infested at the whorl stage exhibited substantial variation in the number of surviving larvae, number of tunnels, and tunnel length, and certain cultivars consistently ranked in the lower or upper quartiles (Table 2). In 1997, 'GH2690' and 'Code 243' consistently showed relatively high resistance, while 'Rival' was consistently susceptible as measured by number of larvae, number of tunnels, and cumulative length of tunnels. Although less consistent in their rankings, 'Code 22' and 'GH1703' showed substantial susceptibility, as well. In 1998, 'Code 243', 'GH2690', 'Bold', and 'Excalibur' all had fairly high resistance to $\mathrm{ECB}$, as measured by larval number, tunnel number, or cumulative tunnel length. In contrast, 'Code 22', 'GH1703', 'Reward', 'Rival', and 'Sprint' all had relatively high susceptibility.

Susceptibility, characterized by a large cumulative tunnel length, could be expressed in two ways. A large number of tunnels, whether short or long, can result in a large cumulative tunnel length. Alternatively, a few very long tunnels could cause a similar amount of damage. The first hypothesis is substantiated by the data from both years. In 1997, 'Rival' and 'Code 22' had many tunnels, and as a consequence, stalk damage was heavy. In contrast, 'GH2690' and 'Code 243' had few tunnels and low damage (Table 2). In 1998 , the pattern was similar, and those cultivars with high numbers of tunnels had more damage, while those with few tunnels had slight damage. We could not substantiate the second hypothesis, that few tunnels of great length would cause heavy damage. Nor could we substantiate the converse, that more tunnels of shorter length might cause less damage. Although there were differences in the length of individual tunnels among corn cultivars, in neither year did a short length per tunnel attenuate the damage caused by a large number of tunnels. The correlation was strong between number of tunnels and cumulative tunnel length, with a correlation coefficient of $0.75(P=0.0053, N=12)$ in 1997 , and 0.974 $(P=0.0001, N=18)$ in 1998 . The correlation between length per tunnel and cumulative tunnel length was much weaker (not significant in 1997; in $1998, R=0.622, P=0.0059$, $N=18$ ), indicating that number of tunnels was a better predictor of cumulative tunnel length than was length per tunnel. Clearly, corn cultivars that allowed greater larval entry and survival also allowed more extensive feeding. Thus, based on the above arguments and observations, neonatal larval mortality, and subsequently few tunnels, was probably the more important of the two possible mechanisms (sensu latu) of resistance.

Ear damage rankings were similar to stalk damage rankings for both years, confirming that there are differences in ECB susceptibility among commercial processing sweet corn cultivars (Table 2). The similarities in the rankings for corn infested at the silk and whorl stages indicates that the 9-point scale we employed adequately detected differences in susceptibility among cultivars. However, we concur with Warnock and Davis (1998) that there may be problems associated with using that scale, particularly in breeding research. The scale is nonlinear with respect to actual area consumed and a rather small feeding wound in the side of the ear will cause a disproportionately high damage rating relative to the same injury in the tip of the ear. Until it can be demonstrated that damage to the side of the ear is not random, we also urge caution in using the 9-point visual evaluation of ear damage.

Possible criticisms of this research may be the numerous infestation dates for ear infestations and the potential effect of the long duration to harvest in the 1998 study of plants infested at the whorl stage. Although neonates are influenced by environmental conditions, those conditions are mitigated somewhat by the high humidity surrounding the silks, and, historically, the method has been reliable for establishing a larval population within the plant. The effect of a protracted harvest interval in 1998 is unknown. Harvest occurred after a typical commercial duration in 1997, but was delayed 2-3 weeks for some cultivars in the 1998 trial in order to allow the ears of later cultivars to mature. Conceivably, evaluating damage after the normal duration to harvest would allow the concurrence of a particularly susceptible phase of growth, and later maturing cultivars would manifest less damage than earlier maturing ones. However, several arguments suggest that harvesting late did not exacerbate the differences among cultivars: 1) we know of no specific maturation period when vegetative damage is best measured; 2) cultivars had similar rankings in 1997 and 1998; 3) within years, rankings from silk- and whorlinfested plots were similar, independent of duration to harvest; and 4) although the length per tunnel may be influenced by corn phenology, tunnel number alone was a good predictor of damage, and was independent of duration to harvest.

The results of our study can be used in various ways. In the short term, sweet corn genotypes with identified resistance to ECB can be incorporated in commercial corn production to minimize corn borer damage. This may be particularly important when insecticides are not used to control ECB. Where insecticides are used, damage thresholds could be modified to reflect the contribution of resistance. Typically, damage thresholds are not adjusted to account for differences in cultivar susceptibility, and in light of the rapid turnover in cultivars, determining thresholds for each susceptibility class would not be reasonable. Instead, thresholds could be adjusted using empirically derived knowledge.

In the longer term, our results can help shape programs that breed for resistance to ECB. Since promising sources of resistance are typically backcrossed with horticulturally acceptable cultivars, backcrossing with those cultivars possessing relatively strong resistance to ECB seems logical. Coincidentally, in a breeding effort conducted by Dr. Margaret Smith that preceded our research, test crosses between subtropical dent cultivars and the commercial 'GH2690' have performed well in resistance screens (unpublished data). At present, the mechanisms of resistance (sensu strictu) are not known, but the effects that were measured in this study may contribute to their identification. Additionally, our research exposed another phenomenon that may have practical implications. We found that the earliest maturing cultivars were the most damaged by corn borer, and that later cultivars were more resistant. The negative correlation between maturation rate and resistance was significant for both $1997(R=-0.34, P=$ $0.008, N=60)$ and $1998(R=-0.70, P=$ $0.0001, N=73$ ). Carlson and Andrew (1976) also found a similar correlation between earliness and susceptibility. Further evaluation of this trend will be necessary to determine if there is a strong link between maturation rate and susceptibility. The relationship we observed may merely be an artifact of the experimental particulars, or the early cultivars may have had common susceptible parentage.

Lastly, our study intensifies the need to explore whether ECB ovipositional preference can be manipulated to our advantage. Previous research suggests that this may be a promising area of research (Andrew and Carlson, 1976; Barry and Darrah, 1988; Derridj et al., 1986; Everly et al., 1979 ). Ovipositional avoidance may preclude the need for resistance of the types described above. Alternatively, the combination of ovipositional avoidance and identified resistance would provide broad-based control of ECB. 


\section{Literature Cited}

Andrew, R.H. and J.R. Carlson Jr. 1976. Preference differences of egg laying European corn borer adults among maize genotypes. HortScience. 11:143.

Barry, D. and L.L. Darrah. 1988. Nonpreference resistance to European corn borer (Lepidoptera: Pyralidae) in the Mo-2 ECB maize cultivar. J. Kansas Entomol. Soc. 61:72-75.

Carlson, J.R., Jr. and R.H. Andrew. 1976. Parameters for determination of damage to sweet corn genotypes from first and second generation $\mathrm{Eu}-$ ropean corn borer. Crop Sci. 16: 39-42.

Cornell Cooperative Extension Service. 1999. Integrated crop and pest management recommendations for commercial vegetable production. Cornell Coop. Ext. Serv.

Davis, D.W., D.A. Andow, and W.D. Hutchison. 1993. Registration of three European corn borer resistant sweet corn germplasm lines: A684su, A685su, and A686su. Crop Sci. 33:1422-1423.

Derridj, S., V. Fiala, and E. Jolivet. 1986. Increase of European corn borer (Ostrinia nubilalis) oviposition induced by a treatment of maize plants with maleic hydrazide: Role of leaf carbohydrate content. Entomol. Expt. and Appl. 41:305-310.
Eckenrode, C.J., P. S. Robbins, and J.T. Andaloro 1983. Variations in flight patterns of European corn borer (Lepidoptera: Pyralidae) in New York Environ. Entomol. 12:393-396.

Everly, R.T, W.D. Guthrie, and F.F. Dicke. 1979. Attractiveness of corn genotypes to ovipositing European corn borer moths. Agr. Rev. and Manuals. U.S. Dept. of Agr. (No. ARM-NC-8).

Grier, S.L. and D.W. Davis. 1980. General and specific relative ovipositional antixenosis (nonpreference) and absolute ovipositional antixenosis conditioned by maize genotypes to the European corn borer. HortScience 15:418.

Guthrie, W.D. 1971. Resistance of maize to second brood European corn borer. p. 165-179. In: Proc. 26 ${ }^{\text {th }}$ Annu. Corn and Sorghum Conf.

Guthrie, W.D., W.A. Russell, G.L. Reed, A.R Hallauer, and D.F. Cox. 1978. Methods of evaluating maize for sheath-collar-feeding resistance to the European corn borer. Maydica 23:45-53.

Jones, D. 1984. Use, misuse, and role of multiplecomparison procedures in ecological and agricultural entomology. Environ. Entomol. 16:635-649.

Jones, D. and N. Matloff. 1986. Statistical hypoth- esis testing in biology: A contradiction in terms. J. Econ. Entomol. 79:1156-1160.

Metcalf, R.L. and R.A. Metcalf. 1993. Destructive and useful insects: Their habits and control 5th ed. McGraw Hill, New York.

National Agricultural Statistics Service, 1997. Agricultural chemical usage. Natl. Agr. Stat. Serv.

National Agricultural Statistics Service, 1998. Vegetable 1997 Summary. Natl. Agr. Stat. Serv.

National Agricultural Statistics Service, 1999. Vegetable 1998 Summary. Natl. Agr. Stat. Serv.

Shehata, M.A., J.C. Hargraves, and D.W. Davis. 1975. A new technique for determining resistance of sweet corn to second-brood European corn borer. HortScience 10:277-278.

Warnock, D.F. and D.W. Davis. 1998. Comparison of two visual scales for estimating European corn borer ear damage in maize. HortScience 33:1048-1049.

Warnock, D.F., D.W. Davis, and G.R. Gingera. 1998. Inheritance of ear resistance to European corn borer in 'Apache' sweet corn. Crop Sci. 38:1451-1457.

Wiseman, B.R., F.M. Davis, and J.E. Campbell. 1980. Mechanical infestation device used in fall armyworm plant resistance programs. Florida Entomol. 63:425-432. 